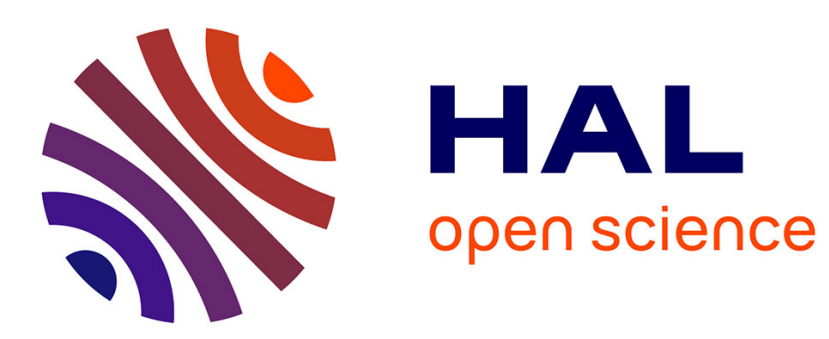

\title{
Scheduling of Real-Time Embedded Systems under Reliability and Power Constraints
}

\author{
Ismail Assayad, Alain Girault, Hamoudi Kalla
}

\section{To cite this version:}

Ismail Assayad, Alain Girault, Hamoudi Kalla. Scheduling of Real-Time Embedded Systems under Reliability and Power Constraints. International Conference on Complex Systems, ICCS'12, Nov 2012, Agadir, Morocco. hal-00777723

\section{HAL Id: hal-00777723 \\ https://hal.inria.fr/hal-00777723}

Submitted on 17 Jan 2013

HAL is a multi-disciplinary open access archive for the deposit and dissemination of scientific research documents, whether they are published or not. The documents may come from teaching and research institutions in France or abroad, or from public or private research centers.
L'archive ouverte pluridisciplinaire HAL, est destinée au dépôt et à la diffusion de documents scientifiques de niveau recherche, publiés ou non, émanant des établissements d'enseignement et de recherche français ou étrangers, des laboratoires publics ou privés. 


\section{Scheduling of Real-Time Embedded Systems under Reliability and Power Constraints}

\author{
Ismail Assayad \\ RTSE team, ENSEM \\ University Hassan II of Casablanca \\ Route El Jadida, Casablanca - Morroco \\ Ismail.Assayad@ensem.ac.ma
}

\author{
Alain Girault \\ POPART team, INRIA \\ 655 av. de l'Europe \\ 3833 Saint-Ismier, Cedex - France \\ Alain.Girault@inrialpes.fr
}

\author{
Hamoudi Kalla \\ REDS team \\ University of Batna \\ Av Chahid Boukhlouf, Batna - Algeria \\ Hamoudi.Kalla@univ-batna.dz
}

\begin{abstract}
In this paper, we present a new tri-criteria scheduling heuristic for scheduling data-flow graphs of operations onto parallel heterogeneous architectures according to three criteria: first the minimization of the schedule length crucial for real-time systems, second the maximization of the system reliability crucial for dependable systems, and third minimizing energy consumption crucial for autonomous systems. The proposed algorithm is a list scheduling heuristics, It uses the active replication of operations to improve the reliability and the dynamic voltage scaling to minimize the energy consumption.
\end{abstract}

Keywords: Distributed real-time systems, safety-critical systems, reliability, multi-criteria scheduling, heterogeneous systems, active software replication.

\section{Introduction}

Distributed systems are being increasingly used in critical real-time applications, such as avionics, air traffic control, autopilot systems, and nuclear plant control, in which the consequences of missing a tasks deadline may cause catastrophic loss of money, time, or even human life. This is why such systems require a high reliability. Here, reliability is defined as the probability that none of the system components will fail while processing.

We present a scheduling heuristics that, from a given software application graph and a given multiprocessor architecture, produces a static multiprocessor schedule that optimizes three criteria: its length (crucial for real-time systems), its reliability (crucial for dependable systems), and its power consumption (crucial for autonomous systems).

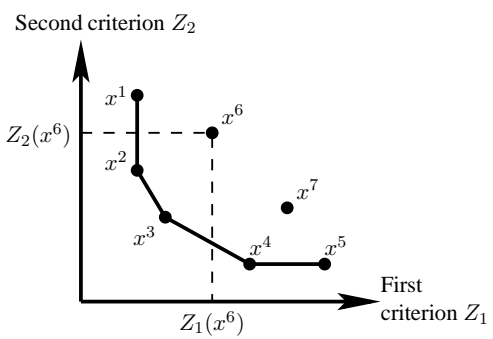

Fig. 1. Pareto optima and Pareto curve for a bicriteria minimization problem.

Let us address the issues raised by multicriteria optimization. Figure 1(a) illustrates the particular case of two criteria to be minimized. Each point $x^{1}$ to $x^{7}$ represents a solution, that is, a different tradeoff between the $Z_{1}$ and $Z_{2}$ criteria: the points $x^{1}, x^{2}$, $x^{3}, x^{4}$, and $x^{5}$ are Pareto optima [13]; the points $x^{1}$ and $x^{5}$ are weak

Ismail Assayad is with ENSEM (RTSE team). Partially funded by DEV-RS 2011/14 CNRST project.

Alain Girault is with INRIA and Grenoble University (POP ART projectteam and LIG laboratory), France.

Hamoudi Kalla is with the University of Batna (REDS team), Algeria. optima while the points $x^{2}, x^{3}$, and $x^{4}$ are strong optima. The set of all Pareto optima is called the Pareto curve.

It is fundamental to understand that no single solution among the points $x^{2}, x^{3}$, and $x^{4}$ (the strong Pareto optima) can be said, a priori, to be the best one. Indeed, those three solutions are non-comparable, so choosing among them can only be done by the user, depending on the precise requirements of his/her application.

The main contribution of this paper is TSH, the first tricriteria scheduling heuristics able to produce, starting from an application algorithm graph and an architecture model, a set of Pareto solutions in the space (length, reliability, power), and taking into account the relationship between the reliability and the voltage level. In addition, the power consumption of both operations and data-dependencies are considered in this paper and the soundness of TSH is demonstrated.

\section{Related work}

Many solutions exist in the literature to optimize the schedule length and the energy consumption (e.g., [10]), or to optimize the schedule length and the reliability (e.g., [5]), but very few tackle the problem of optimizing the three criteria (length,reliability,energy). The closest to our work are [11], [14].

Zhu et al. have studied the impact of the supply voltage on the failure rate [14], in a passive redundancy framework (primary backup approach). They use DFS and DVS to lower the energy consumption and they study the tradeoff between the energy consumption and the performability (defined as the probability of finishing the application correctly within its deadline in the presence of faults).However, their input problem is not a multiprocessor scheduling one since they study the system as a single monolithic operation executed on a single processor.

Pop et al. have addressed the tricriteria optimization problem (length,reliability,energy) on an heterogeneous architecture with a reliable bus [11]. Both the length and the reliability are taken as a constraint, respectively with a given upper and lower bound. However, it is assumed that the user will specify the number of processor failures to be tolerated (with re-execution or passive replication) in order to satisfy the desired reliability constraint.

\section{Models}

\section{A. Application algorithm graph}

Most embedded real-time systems are reactive, and therefore consist of some algorithm executed periodically, triggered by a periodic execution clock. Our model is therefore that of an application algorithm graph $\mathcal{A l g}$ which is repeated infinitely. $\mathcal{A l g}$ is an acyclic oriented graph $(\mathcal{X}, \mathcal{D})$. Its nodes (the set $\mathcal{X}$ ) are software blocks called operations. Each arc of $\mathcal{A l g}$ (the set $\mathcal{D}$ ) is a data-dependency between two operations. If $X \triangleright Y$ is a data-dependency, then $X$ is a predecessor operation of operation $Y$, while $Y$ is a successor operation of $X$. Operation $X$ is also called the source of the data-dependency $X \triangleright Y$, 